\title{
Moderate alcohol consumption increases insulin sensitivity and $A D I P O Q$ expression in postmenopausal women: a randomised, crossover trial
}

\author{
M. M. Joosten • J. W. J. Beulens • S. Kersten • \\ H. F. J. Hendriks
}

Received: 7 March 2008 / Accepted: 7 April 2008/Published online: 27 May 2008

(C) The Author(s) 2008

\begin{abstract}
Aims/hypothesis To determine whether 6 weeks of daily, moderate alcohol consumption increases expression of the gene encoding adiponectin $(A D I P O Q)$ and plasma levels of the protein, and improves insulin sensitivity in postmenopausal women.

Methods In a randomised, open-label, crossover trial conducted in the Netherlands, 36 apparently healthy postmenopausal women who were habitual alcohol consumers, received $250 \mathrm{ml}$ white wine ( $25 \mathrm{~g}$ alcohol/day) or $250 \mathrm{ml}$ of white grape juice (control) daily during dinner for 6 weeks. Randomisation to treatment allocation occurred according to BMI. Insulin sensitivity and $A D I P O Q$ mRNA and plasma adiponectin levels were measured at the end of both periods. Insulin sensitivity was estimated using the homeostasis model assessment of insulin resistance (HOMA-IR). Levels of $A D I P O Q$ mRNA in subcutaneous adipose tissue were determined by RT-PCR.

Results All subjects completed the study. Six weeks of white wine consumption reduced fasting insulin (mean \pm SEM 40.0 \pm 3.4 vs $46.5 \pm 3.4 \mathrm{pmol} / 1 ; p<0.01)$ and HOMA-IR $(1.42 \pm$ 0.13 vs $1.64 \pm 0.13 ; p=0.02)$ compared with 6 weeks of grape juice consumption. $A D I P O Q$ mRNA levels $(1.09 \pm$ 0.15 vs $0.98 \pm 0.15 ; p=0.04)$ and plasma levels of total (13.1
\end{abstract}

\footnotetext{
M. M. Joosten $(\varangle) \cdot J$. W. J. Beulens $\cdot$ H. F. J. Hendriks Business Unit Biosciences, TNO Quality of Life,

P. O. Box 360, 3700 AJ Zeist, the Netherlands

e-mail: michel.joosten@wur.nl

e-mail: michel.joosten@tno.nl
}

M. M. Joosten · J. W. J. Beulens $\cdot$ S. Kersten

Division of Human Nutrition, Wageningen University,

Wageningen, the Netherlands \pm 0.8 vs $12.0 \pm 0.8 \mu \mathrm{g} / \mathrm{ml} ; p<0.001)$ and high molecular weight (HMW) adiponectin ( $9.9 \pm 1.2$ vs $8.8 \pm 1.2 \mu \mathrm{g} / \mathrm{ml} ; p=$ 0.02 ) significantly increased after alcohol compared with juice consumption. Changes in $A D I P O Q$ mRNA levels correlated with changes in plasma levels of total adiponectin $(\rho=0.46 ; p<0.01)$. Both fasting triacylglycerol $(8.2 \% ; p=$ $0.04)$ and LDL-cholesterol levels $(7.8 \% ; p<0.0001)$ decreased, whereas HDL-cholesterol increased $(7.0 \% ; p<$ $0.0001)$ after prolonged moderate alcohol intake. No notable adverse effects were reported.

Conclusions/interpretation Moderate alcohol consumption for 6 weeks improves insulin sensitivity, adiponectin levels and lipid profile in postmenopausal women. Furthermore, these data suggest a transcriptional mechanism leading to the alcohol-induced increase in adiponectin plasma levels.

Trial registration: ClinicalTrials.gov ID no.: NCT00285909 Funding: Partly funded by the Dutch Foundation for Alcohol Research (SAR).

Keywords Adiponectin - Alcohol consumption . Gene expression · High molecular weight adiponectin . Insulin sensitivity · Lipid profile · Peroxisome proliferatoractivated receptor gamma $\cdot$ Postmenopausal women

$\begin{array}{ll}\text { Abbreviations } \\ \text { EtG } & \begin{array}{l}\text { ethyl glucuronide } \\ \text { high molecular weight } \\ \text { HMW }\end{array} \\ \text { HOMA-IR } & \begin{array}{l}\text { homeostasis model assessment } \\ \text { of insulin resistance } \\ \text { plasminogen activator inhibitor 1 }\end{array} \\ \text { PAI-1 } & \begin{array}{l}\text { peroxisome proliferator-activated receptor } \\ \text { PPAR }\end{array}\end{array}$




\section{Introduction}

Moderate alcohol consumption has consistently been associated with a decreased risk of type 2 diabetes compared with abstaining and excessive drinking [1, 2]. The reason for the lower risk of type 2 diabetes is not entirely clear but a plausible explanation seems to be improved insulin sensitivity [3]. However, so far only one randomised controlled trial among postmenopausal women has confirmed this notion [4]. Other studies, mainly performed among young male populations, failed to detect such effects [5-12].

Adiponectin, an adipose tissue-derived hormone, is thought to play an important role in the regulation of insulin sensitivity and glucose and lipid metabolism [13]. Its plasma levels are positively associated with insulin sensitivity [14] and are inversely associated with impaired glucose metabolism and type 2 diabetes [15-17]. Furthermore, observational studies revealed an association between moderate alcohol consumption, adiponectin concentrations and insulin sensitivity [18, 19]. Randomised controlled trials also showed a significant increase in the circulating levels of both total and high molecular weight (HMW) adiponectin [6-8] after a period of moderate alcohol consumption compared with abstention.

However, the mechanism by which moderate alcohol consumption increases adiponectin levels is unknown. Synthesis of adiponectin is controlled by peroxisome proliferator-activated receptor $\gamma$ (PPAR- $\gamma$ ) activation, which functions as a transcriptional regulator [20]. Low doses of alcohol have been shown to alter the expression of the genes encoding tissue plasminogen activator (PLAT) and plasminogen activator inhibitor type-1 (PAI-1 also known as SERPINE1) [21]. Like adiponectin, these markers are affected by moderate alcohol consumption and activated by PPAR- $\gamma[22]$.

Consequently, we investigated whether moderate alcohol consumption affects expression of the gene encoding adiponectin $(A D I P O Q)$ and levels of the protein, and whether it improves insulin sensitivity in postmenopausal women.

\section{Methods}

Study protocol The study used a randomised, open label, placebo-controlled, crossover design, consisting of two 6 week periods, each preceded by 1 week of washout. Participants consumed $250 \mathrm{ml}$ of white wine $(25 \mathrm{~g}$ alcohol; Chardonnay; Jean d'Alibert, Rieux, France) or alcohol-free white grape juice (Albert Heijn, Zaandam, the Netherlands) daily for 6 weeks during dinner. The study was conducted at TNO (a Dutch acronym for the Netherlands organisa- tion for applied scientific research) Quality of Life, Zeist, the Netherlands. The primary objective of the study was to investigate the effect of moderate alcohol consumption on PPAR- $\gamma$ activity and risk markers of metabolic disease, and it took place between March and June 2006. Participants were instructed to maintain their habitual body weight, food pattern and physical activity pattern and were told to refrain from any alcoholic products during the entire study (including washout periods) except for alcoholic beverages supplied by TNO. Of the 77 women who were screened, 40 were eligible to participate. A total of 36 women were randomly selected and initiated the study. Allocation to treatment order was randomised according to BMI. Both white wine and white grape juice contained $300 \mathrm{~kJ} / 100 \mathrm{ml}(\sim 70 \mathrm{kcal} / 100 \mathrm{ml})$. Blood and adipose tissue sampling was done on the last day of each treatment period after an overnight fast. Compliance was monitored by weekly measurement of urinary ethyl glucuronide (EtG), a direct phase II metabolite of ethanol formed by the action of UDP-glucuronosyl transferase. EtG has been reported to be a superior marker, with $100 \%$ sensitivity as a biomarker of recent drinking [23]. It persists in the urine up to $\sim 75-85 \mathrm{~h}$ after the last intake. Additional measures of compliance were an increase in HDL-cholesterol, daily questionnaires, and return of empty bottles.

Participants Postmenopausal women were recruited from a pool of volunteers from TNO Quality of Life and by advertisements in local newspapers. Eligible participants consumed between 5 and 21 units of alcohol per week, were apparently healthy and had an absence of menses for at least 2 years, a BMI between 18.5 and $35 \mathrm{~kg} / \mathrm{m}^{2}$ and no family history of alcoholism. Participants gave written informed consent and received compensation for their participation. An independent medical ethics committee (The Medical Ethics Committee of the University Medical Centre Utrecht) approved the research protocol.

Outcome measures Primary endpoints were markers of insulin sensitivity, such as homeostasis model assessment of insulin resistance (HOMA-IR), calculated as [fasting serum insulin (in $\mu \mathrm{U} / \mathrm{l}$ ) $\times$ fasting serum glucose (in $\mathrm{mmol} / \mathrm{l}$ )] $/ 22.5$ [5], glucose, insulin, and several adiponectin-related measures, such as $A D I P O Q$ mRNA levels and plasma levels of total and HMW adiponectin. Secondary variables included lipid profile (triacylglycerol and HDL- and LDL-cholesterol) $\mathrm{HbA}_{1 \mathrm{c}}$ and NEFA and correlations between specific outcome measures.

Analyses and assessment Ethyl glucuronide was determined in morning urine samples. Urinary samples were diluted about 20 -fold using an internal standard solution. The resulting solution was analysed using a triple quadru- 
Table 1 Characteristics of 36 postmenopausal women before intervention

\begin{tabular}{lc}
\hline Variable & Baseline value \\
\hline Age (years) & $56.5 \pm 4.2$ \\
Weight $(\mathrm{kg})$ & $71.4 \pm 10.0$ \\
BMI $\left(\mathrm{kg} / \mathrm{m}^{2}\right)$ & $25.4 \pm 3.3$ \\
Fasting glucose (mmol/l) & $5.5 \pm 0.4$ \\
Fasting insulin (pmol/l) & $37.4 \pm 12.6$ \\
Fasting triacylglycerol (mmol/l) & $1.21 \pm 0.54$ \\
HDL-cholesterol (mmol/l) & $1.67 \pm 0.27$ \\
LDL-cholesterol (mmol/l) & $3.88 \pm 0.60$ \\
Total cholesterol (mmol/l) & $6.11 \pm 0.72$ \\
Alkaline phosphatase (U/l) & $76.1 \pm 19.3$ \\
Alanine aminotransferase (U/l) & $15.3 \pm 8.2$ \\
Aspartate aminotransferase (U/l) & $20.8 \pm 7.4$ \\
-Glutamyltranspeptidase (U/l) & $21.3 \pm 11.4$ \\
Follicle-stimulating hormone (IU/l) & $108.5 \pm 41.3$ \\
\hline
\end{tabular}

Data are mean \pm SD

pole Ultra Performance LC/MS in MRM mode (Waters, Saint-Quentin en Yvelines, France) with a detection limit of $50 \mathrm{ng} / \mathrm{ml}$. The cut-off limit to assess compliance during juice intervention for urinary $\mathrm{EtG}$ values was set at $>0.25 \mathrm{mg} / \mathrm{ml}$ (positive sample), to obtain high sensitivity but avoid positive results due to unintentional ethanol exposure. The cut-off limit during wine intervention was set at $\mathrm{EtG}<0.5 \mathrm{mg} / \mathrm{ml}(2.2 \mu \mathrm{mol} / \mathrm{l})$ (negative sample), as proposed by Bottcher et al. [24]. Blood samples were obtained from the antecubital vein of the forearm and collected in tubes containing clot activator for serum and in ice-chilled tubes containing or potassium ethylenediamine tetraacetic acid $\left(\mathrm{K}_{3}\right.$ EDTA) for plasma (Vacutainer Systems, Becton Dickinson, Plymouth, UK). Blood was centrifuged for $15 \mathrm{~min}$ at $2,000 \times \mathrm{g}$ at $4^{\circ} \mathrm{C}$ within $15-30 \mathrm{~min}$ after collection and stored at $-80^{\circ} \mathrm{C}$. All biochemical determinations in blood were performed at TNO Quality of Life using Olympus analytical equipment and reagents except for adiponectin. Plasma total adiponectin concentrations were determined by RIA (Linco Research, St Charles, MO, USA) with a mean intra-assay coefficient of variation of $5.0 \%$, and plasma HMW adiponectin levels were determined by a novel ELISA (Linco Research) with a mean intra-assay coefficient of variation of $14.1 \%$. LDL-cholesterol was calculated using the Friedewald formula. Subcutaneous adipose tissue was sampled from the buttock by means of a Strauss cannula, outer diameter $1.5 \mathrm{~mm}$, and stored at $-70^{\circ} \mathrm{C}$ until further analysis. Total RNA was extracted from adipose tissue with TRIzol reagent (Invitrogen, Breda, the Netherlands); $1 \mathrm{mg}$ total RNA was then reverse-transcribed with iScript (Bio-Rad, Veenendaal, the Netherlands). cDNA was PCR-amplified with Platinum Taq DNA polymerase (Invitrogen) on an iCycler (Bio-Rad) or MyIQ (Bio-Rad) PCR machine. Expression was standardised to the level of acidic ribosomal protein $A R B P$ [25]. Primer sequences used were as follows: $A D I P O Q$ forward, TATCCCCAACATG CCCATTCG; $A D I P O Q$ reverse, TGGTAGGCAAAGTAG TACAGCC; PPARG forward, TCCATGCTGTTATGGGT GAA; $P P A R G$ reverse, TCAAAGGAGTGGGAGTGGTC; $A R B P$ forward, CGGGAAGGCTGTGGTGCTG; ARBP reverse, GTGAACACAAAGCCCACATTCC.

Statistical analyses Statistical analyses were performed using the SAS statistical software package (SAS version 8; SAS Institute, Cary, NC, USA). All variables were compared between treatments with a mixed analysis of variance model that included terms for treatment, period and the interaction between period and treatment (indicat-
Table 2 Markers of insulin sensitivity, adiponectin and lipid profile in 36 postmenopausal women measured at the end of a 6 week period of consuming white grape juice or white wine

Data are mean \pm SEM

\begin{tabular}{lccr}
\hline Variable & Grape juice & White wine & $p$ value \\
\hline Insulin sensitivity & & & \\
HOMA-IR & $1.64 \pm 0.13$ & $1.42 \pm 0.13$ & 0.02 \\
Fasting insulin (pmol/l) & $46.5 \pm 3.4$ & $40.0 \pm 3.4$ & $<0.01$ \\
Fasting glucose (mmol/l) & $5.4 \pm 0.1$ & $5.4 \pm 0.1$ & 0.72 \\
HbA $_{1 \mathrm{c}}(\%)$ & $6.0 \pm 0.04$ & $5.9 \pm 0.04$ & 0.09 \\
Fasting NEFA (mmol/l) & $0.43 \pm 0.04$ & $0.44 \pm 0.04$ & 0.67 \\
Body weight $(\mathrm{kg})$ & $70.4 \pm 1.7$ & $71.1 \pm 1.7$ & $<0.001$ \\
Adiponectin & & & \\
ADIPOQ/ARBP mRNA (arbitrary units) & $0.98 \pm 0.15$ & $1.09 \pm 0.15$ & 0.04 \\
$P P A R G / A R B P$ mRNA (arbitrary units) & $0.67 \pm 0.09$ & $0.73 \pm 0.09$ & 0.13 \\
Fasting total adiponectin $(\mu \mathrm{g} / \mathrm{ml})$ & $12.0 \pm 0.8$ & $13.1 \pm 0.8$ & $<0.001$ \\
Fasting HMW adiponectin $(\mu \mathrm{g} / \mathrm{ml})$ & $8.8 \pm 1.2$ & $9.9 \pm 1.2$ & 0.02 \\
Lipid profile & & & \\
Fasting triacylglycerol (mmol/l) & $1.18 \pm 0.08$ & $1.03 \pm 0.08$ & 0.04 \\
HDL-cholesterol (mmol/l) & $1.57 \pm 0.04$ & $1.68 \pm 0.04$ & $<0.0001$ \\
LDL-cholesterol (mmol/l) & $3.84 \pm 0.12$ & $3.51 \pm 0.12$ & $<0.0001$ \\
\hline
\end{tabular}


ing possible carryover effects). Body weight was included in the model as a random factor to adjust for changes in body weight. Correlation coefficients were computed according to Spearman rank order to assess associations between intervention-induced changes in outcome measures. Based on a study by Arvidsson et al. [26], a sample size of 36 was considered sufficient to detect a $20 \%$ difference in $A D I P O Q$ mRNA levels with a power of $80 \%$, accepting a two-sided $\alpha$ of 0.05 . Data are presented as mean \pm SEM unless otherwise specified. Statistical significance was defined as $p<0.05$.

\section{Results}

General results All 36 postmenopausal women completed the study. Participants were slightly overweight (BMI 25.4 $\pm 3.3 \mathrm{~kg} / \mathrm{m}^{2}$ ). Mean glucose, insulin, triacylglycerol and cholesterol concentrations before the intervention indicated that participants were euglycaemic and normolipidaemic (Table 1).

Compliance with treatments was assessed by weekly urinary EtG, revealing two positive samples during the juice-drinking period and six negative samples during the wine-drinking period out of the 468 samples analysed (overall compliance 98.3\%). Another indicator of compliance was the $7.0 \%$ higher level of HDL-cholesterol after wine consumption compared with the value after juice consumption (Table 2).

No significant $(p>0.05)$ carryover effects, as assessed by interaction between treatment and period effects, were observed for any outcome measures. Treatment means of variables and $p$ values estimated from models with period effects were very similar to those obtained from models without a period effect, and we report the results of the latter. Mean body weight was $0.7 \mathrm{~kg}$ higher $(p<0.001)$ at the end of the wine-drinking period than at the end of the juice-drinking period (Table 2). Results were adjusted for this difference in body weight but did not essentially change them. Therefore, unadjusted results are presented here.

Insulin sensitivity Fasting serum insulin concentration was lower (by $12.3 \% ; p<0.01$ ) and the $\mathrm{HbA}_{1 \mathrm{c}}$ percentage tended to be lower $(p=0.09)$ after 6 weeks of moderate alcohol consumption than after 6 weeks of abstention. Insulin sensitivity, as expressed by the HOMA-IR index, improved by $11.9 \%(p=0.02)$ after white wine consumption compared with that following juice consumption. However, serum glucose and NEFA concentrations did not differ significantly between the two interventions at the end of the intervention period (Table 2).
Adiponectin There was a significant increase in the relative $A D I P O Q$ mRNA levels in subcutaneous adipose tissue $(27.7 \% ; p=0.04)$ of women who consumed alcohol in moderation for 6 weeks compared with those who consumed juice. Consistently, the ratio of PPARG/ARBP mRNA levels also tended to increase, although not significantly $(p=0.13)$, after the alcohol treatment. Plasma protein levels of total adiponectin $(10.6 \% ; p<0.001)$ and HMW adiponectin $(15.8 \% ; p=0.02)$ increased significantly after consuming white wine, rather than juice, for 6 weeks (Table 2).

Lipid profile Besides a significant increase in HDL-cholesterol, changes in lipid profile were further characterised by significantly lower levels of LDL-cholesterol $(7.8 \% ; p<$ $0.001)$ and triacylglycerol $(8.2 \% ; p=0.04)$ after the winedrinking period compared with the juice-drinking period (Table 2).

Correlations Changes in $A D I P O Q$ mRNA levels due to alcohol consumption correlated positively with changes in PPARG mRNA levels $(\rho=0.76 ; p<0.001)$ and with changes in the plasma protein level of total adiponectin $(\rho=0.46 ; p<$ 0.01 ), but not with changes in plasma levels of HMW adiponectin $(\rho=-0.25 ; p=0.15)$. No significant correlations were found between changes in HOMA-IR and changes in plasma levels of total adiponectin $(\rho=0.27 ; p=0.11)$ or HMW adiponectin $(\rho=-0.18 ; p=0.29)$. Furthermore, changes in HDL-cholesterol correlated significantly with changes in total adiponectin $(\rho=0.47 ; p<0.01)$ but not with HMW adiponectin levels $(\rho=0.13 ; p=0.44)$.

\section{Discussion}

The primary findings of this study are that daily, moderate alcohol intake improves insulin sensitivity and lipid profile in postmenopausal women. Furthermore, $A D I P O Q$ mRNA levels in subcutaneous adipose tissue along with plasma levels of total and HMW adiponectin increased after moderate alcohol consumption. Moreover, changes in $A D I P O Q$ mRNA levels correlated with changes in plasma total adiponectin, indicating that prolonged moderate alcohol intake increases circulating adiponectin through increased gene expression. However, improvements in insulin sensitivity were not associated with increased plasma adiponectin levels (HMW and total) after moderate alcohol consumption in these women.

A strength of this study is its randomised crossover design. Another strength is that we assessed compliance to study treatment several times in different ways throughout the study and observed no significant deviations. Several 
limitations warrant consideration. A slightly lower body weight was observed after the juice intervention compared with the alcohol intervention. However, lower body weight is associated with improved insulin sensitivity and thus could have only affected the results towards no alcoholinduced improvement in insulin sensitivity. In the present study, only subcutaneous adipose tissue samples were used to determine $A D I P O Q$ mRNA levels. Studies demonstrated that $A D I P O Q$ mRNA levels were higher [27, 28] or not different [29] in subcutaneous compared with visceral adipose tissue in lean and obese participants. Furthermore, studies in human adipose tissue showed increased [30] as well as similar [31] $A D I P O Q$ mRNA and in vitro adiponectin secretion levels from subcutaneous compared with omental adipocytes. Subcutaneous adipose tissue thus appears to be at least as important as omental adipose tissue for circulating plasma adiponectin levels.

The observed changes in insulin sensitivity after prolonged moderate alcohol intake are in accordance with a study by Davies et al. [4] in which moderate alcohol consumption in postmenopausal women for 8 weeks decreased fasting insulin and triacylglycerol levels-both independent risk factors for type 2 diabetes - and improved insulin sensitivity. However, other clinical trials did not find a change in fasting insulin levels [9] and triacylglycerol levels [32, 33] or in insulin sensitivity after moderate alcohol consumption [5-8, 10, 11], whereas levels of total adiponectin [6, 7] and HMW adiponectin [8] did increase. Differences in the designs used in these clinical trials are numerous. However, studies that did observe an effect on markers of insulin sensitivity after moderate alcohol consumption were all performed in middle-aged [4], relatively insulin-resistant [6] or diabetic people [34, 35]. This suggests that the effect of moderate alcohol intake on insulin sensitivity is more pronounced in people with (slightly) impaired glucose tolerance rather than young and glucose-tolerant people. Moreover, most interventions that did not observe a link between alcohol and insulin sensitivity involved only $30[5,12]$ or even fewer [6$8,11]$ days of consecutive alcohol consumption, while this study and the studies of Davies et al. [4] and Shai et al. [34] lasted 6, 8 and 12 weeks respectively. This indicates that a longer duration of alcohol consumption may be needed to exert an effect on insulin sensitivity. Finally, the relation between moderate alcohol intake and insulin sensitivity might be influenced by sex, since the association between alcohol consumption and type 2 diabetes appears to be stronger in women than in men, as observed in some observational studies [1]. This sex difference may be explained partly by changes associated with menopause, which may mediate the relation between alcohol and triacylglycerol levels, the latter being an independent risk factor for type 2 diabetes [36]. Compared with postmenopausal non-drinkers, postmenopausal drinkers have lower triacylglycerol levels, whereas male drinkers have higher triacylglycerol levels compared with male abstainers [37].

Intervention-associated changes in $A D I P O Q$ mRNA in subcutaneous adipose tissue correlated with changes in plasma protein levels of total adiponectin. In line with this are cross-sectional studies [38, 39] showing associations between subcutaneous $A D I P O Q$ mRNA levels and plasma levels of adiponectin. This finding suggests that the alcohol-induced increase in plasma adiponectin levels is mediated by de novo synthesis rather than decreased renal function [40] or post-transcriptional regulation [41]. Changes in plasma HMW adiponectin did not correlate with changes in $A D I P O Q$ mRNA levels. However, the formation of multimer oligomers of HMW adiponectin is influenced by several post-translational modifications [42], which can account for the absence of such a correlation.

Adiponectin synthesis is under the control of the transcription factor PPAR $-\gamma$ [20]. PPAR- $\gamma$ ligands induce expression of $A D I P O Q$ via direct binding of the PPAR- $\gamma /$ retinoid $\mathrm{X}$ receptor heterodimer to the PPAR-responsive element in the human $A D I P O Q$ promoter. We indeed observed a trend for increased PPARG mRNA levels after the alcohol intervention. However, our sample size of 36 participants was anticipated to detect a $20 \%$ change in mRNA levels. As the intervention gave rise to a change of only $9 \%$ in PPARG mRNA, our study was underpowered to detect a significant difference. Besides this trend for increased PPAR levels, we also found a strong correlation between intervention-associated changes in levels of PPARG and ADIPOQ mRNAs. Furthermore, previous research has shown that $P A I-1$ expression and PAI-1 protein levels increase after alcohol consumption [21]. PAI-1 expression is also regulated by PPAR $-\gamma$ [22]. It thus seems plausible that moderate alcohol use might alter $A D I P O Q$ expression and, consequently, adiponectin protein levels, also in a PPAR- $\gamma$-mediated manner.

Consistent with previous findings in young and middleaged men [6, 7], we now report that total adiponectin plasma levels also increase in postmenopausal women after moderate alcohol consumption. Moreover, we found that the HMW form of plasma adiponectin also increased after 6 weeks of alcohol consumption. The increase in HMW adiponectin after moderate alcohol consumption is in line with a previous study in which a trend was observed [8]. In the present study, however, we used a more sensitive and precise method to quantify HMW adiponectin-ELISA instead of quantitative western blotting.

The observed changes in insulin sensitivity as measured by HOMA-IR did not correlate with the alcohol-induced changes in total or HMW adiponectin, the latter of which is proposed to be a better predictor of insulin sensitivity [43]. 
These findings are consistent with other lifestyle interventions, such as weight loss [44] and exercise interventions [45], and with previous observations of our group [7, 8] which showed increased adiponectin plasma levels without changes in insulin sensitivity. In this study we did find an effect of alcohol on insulin sensitivity irrespective of changes in adiponectin levels. The present results may suggest a possible independent effect of alcohol on insulin sensitivity in addition to an adiponectin-mediated effect on insulin sensitivity.

Looking at our cross-sectional data, we did observe correlations between HOMA-IR and adiponectin levels after both alcohol and placebo treatment (data not shown). This is in line with published literature in which associations between adiponectin and insulin sensitivity have been shown consistently [14-17]. Possibly, increased adiponectin levels partly explain the improved insulin sensitivity seen among moderate alcohol consumers [18, 19]. Studies have revealed that circulating adiponectin levels are inversely associated with markers of inflammation [39, $46,47]$, whereas low-grade inflammation is thought to contribute to insulin resistance [48]. Therefore, adiponectin may lead to improved insulin sensitivity through effects on inflammatory markers.

In conclusion, the results of the present study demonstrate that 6 weeks of moderate alcohol consumption improves insulin sensitivity and the lipid profile in postmenopausal women. Furthermore, moderate alcohol consumption increases subcutaneous adipose $A D I P O Q$ mRNA levels and plasma levels of adiponectin. This suggests that the alcohol-induced increase in adiponectin is attributable, at least in part, to transcriptional alterations in adipose tissue. The observed improvements in insulin sensitivity, lipid profile and adiponectin levels when consuming 2.5 standard drinks per day may reduce the risk of type 2 diabetes and cardiovascular disease in postmenopausal women. Despite these potentially beneficial findings, the scientific literature indicates that alcohol drinking may also have detrimental effects on health [49]. Both potential benefits and risks should be taken into consideration when counselling people about consumption.

Acknowledgements We thank all those involved in the conduct of the study for their efforts. The research described in this article was partly funded by the Dutch Foundation for Alcohol Research (SAR).

Duality of interest The authors declare that there is no duality of interest associated with this manuscript.

Open Access This article is distributed under the terms of the Creative Commons Attribution-Noncommercial License which permits any noncommercial use, distribution, and reproduction in any medium, provided the original author(s) and source are credited.

\section{References}

1. Koppes LLJ, Dekker JM, Hendriks HFJ, Bouter LM, Heine RJ (2005) Moderate alcohol consumption lowers the risk of type 2 diabetes: a meta-analysis of prospective observational studies. Diabetes Care 28:719-725

2. Beulens JWJ, Stolk RP, van der Schouw YT, Grobbee DE, Hendriks HFJ, Bots ML (2005) alcohol consumption and risk of type 2 diabetes among older women. Diabetes Care 28:29332938

3. Hendriks HF (2007) Moderate alcohol consumption and insulin sensitivity: observations and possible mechanisms. Ann Epidemiol 17:S40-S42

4. Davies MJ, Baer DJ, Judd JT, Brown ED, Campbell WS, Taylor PR (2002) Effects of moderate alcohol intake on fasting insulin and glucose concentrations and insulin sensitivity in postmenopausal women: a randomized controlled trial. JAMA 287:2559-2562

5. Zilkens RR, Burke V, Watts G, Beilin LJ, Puddey IB (2003) The effect of alcohol intake on insulin sensitivity in men: a randomized controlled trial. Diabetes Care 26:608-612

6. Sierksma A, Patel H, Ouchi N et al (2004) Effect of moderate alcohol consumption on adiponectin, tumor necrosis factor- $\alpha$, and insulin sensitivity. Diabetes Care 27:184-189

7. Beulens JWJ, de Zoete EC, Kok FJ, Schaafsma G, Hendriks HFJ (2008) Effect of moderate alcohol consumption on adipokines and insulin sensitivity in lean and overweight men: a diet intervention study. Eur J Clin Nutr DOI 10.1038/sj.ejen.1602821

8. Beulens J, van Loon L, Kok F et al (2007) The effect of moderate alcohol consumption on adiponectin oligomers and muscle oxidative capacity: a human intervention study. Diabetologia 50:1388-1392

9. Cordain L, Bryan ED, Melby CL, Smith MJ (1997) Influence of moderate daily wine consumption on body weight regulation and metabolism in healthy free-living males. J Am Coll Nutr 16:134-139

10. Cordain L, Melby CL, Hamamoto AE et al (2000) Influence of moderate chronic wine consumption on insulin sensitivity and other correlates of syndrome $\mathrm{X}$ in moderately obese women. Metabolism 49:1473-1478

11. Beulens JWJ, van Beers RM, Stolk RP, Schaafsma G, Hendriks HFJ (2006) The effect of moderate alcohol consumption on fat distribution and adipocytokines. Obesity Res 14:60-66

12. Gonzalez-Ortiz M, Pascoe-Gonzalez S, Kam-Ramos AM, Martinez-Abundis E (2005) Effect of tequila on homocysteine, insulin secretion, insulin sensitivity, and metabolic profile in healthy men. J Diabetes Complicat 19:155-159

13. Chandran M, Phillips SA, Ciaraldi T, Henry RR (2003) Adiponectin: more than just another fat cell hormone? Diabetes Care 26:2442-2450

14. Tschritter O, Fritsche A, Thamer C et al (2003) Plasma adiponectin concentrations predict insulin sensitivity of both glucose and lipid metabolism. Diabetes 52:239-243

15. Snijder MB, Heine RJ, Seidell JC et al (2006) Associations of adiponectin levels with incident impaired glucose metabolism and type 2 diabetes in older men and women: the Hoorn Study. Diabetes Care 29:2498-2503

16. Snehalatha C, Mukesh B, Simon M, Viswanathan V, Haffner SM, Ramachandran A (2003) Plasma adiponectin is an independent predictor of type 2 diabetes in Asian Indians. Diabetes Care 26:3226-3229

17. Duncan BB, Schmidt MI, Pankow JS et al (2004) Adiponectin and the development of type 2 diabetes: the Atherosclerosis Risk in Communities Study. Diabetes 53:2473-2478

18. Thamer C, Haap M, Fritsche A, Haering H, Stumvoll M (2004) Relationship between moderate alcohol consumption and adiponectin and insulin sensitivity in a large heterogeneous population. Diabetes Care 27:1240 
19. Englund Ogge L, Brohall G, Behre CJ, Schmidt C, Fagerberg B (2006) Alcohol consumption in relation to metabolic regulation, inflammation, and adiponectin in 64-year-old Caucasian women: a population-based study with a focus on impaired glucose regulation. Diabetes Care 29:908-913

20. Iwaki M, Matsuda $M$, Maeda $N$ et al (2003) Induction of adiponectin, a fat-derived antidiabetic and antiatherogenic factor, by nuclear receptors. Diabetes 52:1655-1663

21. Booyse FM, Aikens ML, Grenett HE (1999) Endothelial cell fibrinolysis: transcriptional regulation of fibrinolytic protein gene expression (t-PA, u-PA, and PAI-1) by low alcohol. Alcohol Clin Exp Res 23:1119-1124

22. Marx N, Bourcier T, Sukhova GK, Libby P, Plutzky J (1999) PPARgamma activation in human endothelial cells increases plasminogen activator inhibitor type-1 expression: PPARgamma as a potential mediator in vascular disease. Arterioscler Thromb Vasc Biol 19:546-551

23. Hoiseth G, Bernard JP, Stephanson N et al (2008) Comparison between the urinary alcohol markers EtG, EtS, and GTOL/5-HIAA in a controlled drinking experiment. Alcohol Alcohol 43:187-191

24. Bottcher M, Beck O, Helander A (2008) Evaluation of a new immunoassay for urinary ethyl glucuronide testing. Alcohol Alcohol 43:46-48

25. Joosen AM, Bakker AH, Zorenc AH, Kersten S, Schrauwen P, Westerterp KR (2006) PPARgamma activity in subcutaneous abdominal fat tissue and fat mass gain during short-term overfeeding. Int J Obes (Lond) 30:302-307

26. Arvidsson E, Viguerie N, Andersson I, Verdich C, Langin D, Arner P (2004) Effects of different hypocaloric diets on protein secretion from adipose tissue of obese women. Diabetes 53:1966-1971

27. Hernandez-Morante JJ, Milagro F, Gabaldon JA, Martinez JA, Zamora S, Garaulet M (2006) Effect of DHEA-sulfate on adiponectin gene expression in adipose tissue from different fat depots in morbidly obese humans. Eur J Endocrinol 155:593-600

28. Lihn AS, Bruun JM, He G, Pedersen SB, Jensen PF, Richelsen B (2004) Lower expression of adiponectin mRNA in visceral adipose tissue in lean and obese subjects. Mol Cell Endocrinol 219:9-15

29. Yang WS, Chen MH, Lee WJ et al (2003) Adiponectin mRNA levels in the abdominal adipose depots of nondiabetic women. Int J Obes Relat Metab Disord 27:896-900

30. Fisher FM, McTernan PG, Valsamakis G et al (2002) Differences in adiponectin protein expression: effect of fat depots and type 2 diabetic status. Horm Metab Res 34:650-654

31. Motoshima H, Wu X, Sinha MK et al (2002) Differential regulation of adiponectin secretion from cultured human omental and subcutaneous adipocytes: effects of insulin and rosiglitazone. J Clin Endocrinol Metab 87:5662-5667

32. Rumpler WV, Clevidence BA, Muesing RA, Rhodes DG (1999) Changes in women's plasma lipid and lipoprotein concentrations due to moderate consumption of alcohol are affected by dietary fat level. J Nutr 129:1713-1717

33. Sierksma A, Vermunt SH, Lankhuizen IM et al (2004) Effect of moderate alcohol consumption on parameters of reverse cholesterol transport in postmenopausal women. Alcohol Clin Exp Res 28:662-666
34. Shai I, Wainstein J, Harman-Boehm I et al (2007) Glycemic effects of moderate alcohol intake among patients with type 2 diabetes: a multicenter, randomized, clinical intervention trial. Diabetes Care 30:3011-3016

35. Bantle AE, Thomas W, Bantle JP (2008) Metabolic effects of alcohol in the form of wine in persons with type 2 diabetes mellitus. Metabolism 57:241-245

36. DeFronzo RA, Ferrannini E (1991) Insulin resistance. A multifaceted syndrome responsible for NIDDM, obesity, hypertension, dyslipidemia, and atherosclerotic cardiovascular disease. Diabetes Care 14:173-194

37. Ebrahim S, Lawlor DA, Shlomo YB et al (2008) Alcohol dehydrogenase type 1C (ADH1C) variants, alcohol consumption traits, HDL-cholesterol and risk of coronary heart disease in women and men: British Women's Heart and Health Study and Caerphilly cohorts. Atherosclerosis 196:871-878

38. Kern PA, Di Gregorio GB, Lu T, Rassouli N, Ranganathan G (2003) Adiponectin expression from human adipose tissue: relation to obesity, insulin resistance, and tumor necrosis factor$\alpha$ expression. Diabetes 52:1779-1785

39. Engeli S, Feldpausch M, Gorzelniak K et al (2003) Association between adiponectin and mediators of inflammation in obese women. Diabetes 52:942-947

40. Guebre-Egziabher F, Drai J, Fouque D (2007) Adiponectin and chronic kidney disease. J Ren Nutr 17:9-12

41. Rasouli N, Yao-Borengasser A, Miles LM, Elbein SC, Kern PA (2006) Increased plasma adiponectin in response to pioglitazone does not result from increased gene expression. Am J Physiol Endocrinol Metab 290:E42-E46

42. Wang Y, Lam KS, Yau MH, Xu A (2008) Post-translational modifications of adiponectin: mechanisms and functional implications. Biochem J 409:623-633

43. Hara K, Horikoshi M, Yamauchi T et al (2006) Measurement of the high-molecular weight form of adiponectin in plasma is useful for the prediction of insulin resistance and metabolic syndrome. Diabetes Care 29:1357-1362

44. Bobbert T, Rochlitz H, Wegewitz U et al (2005) Changes of adiponectin oligomer composition by moderate weight reduction. Diabetes 54:2712-2719

45. Bluher M, Brennan AM, Kelesidis T et al (2007) Total and highmolecular weight adiponectin in relation to metabolic variables at baseline and in response to an exercise treatment program: comparative evaluation of three assays. Diabetes Care 30:280-285

46. Ouchi N, Walsh K (2007) Adiponectin as an anti-inflammatory factor. Clin Chim Acta 380:24-30

47. Hung J, McQuillan BM, Thompson PL, Beilby JP (2008) Circulating adiponectin levels associate with inflammatory markers, insulin resistance and metabolic syndrome independent of obesity. Int J Obes (Lond) DOI 10.1038/sj.ijo.0803793

48. Wellen KE, Hotamisligil GS (2005) Inflammation, stress, and diabetes. J Clin Invest 115:1111-1119

49. American Institute for Cancer Research (2007) Food, nutrition, physical activity, and the prevention of cancer: a global perspective. World Cancer Research Fund (WCRF) American Institute for Cancer Research (AICR), Washington DC 